\title{
Prevalence of Human papillomavirus (HPV) and Epstein-Barr virus (EBV) in oral and oropharyngeal squamous cell carcinoma in south-eastern Poland
}

\author{
Dorota Polz-Gruszka', Kamal Morshed ${ }^{2}$, Agnieszka Stec $^{1}$ and Małgorzata Polz-Dacewicz ${ }^{1 *}$
}

\begin{abstract}
Objective: The aim of this study was to analyze the prevalence of HPV and EBV in oral and oropharyngeal squamous cell carcinoma in south-eastern Poland. The correlation between viral infection, OSCC, alcohol use, tobacco smoking, demographic data (gender, age, place of residence), anatomic location, pre-treatment staging, evidence of metastases to lymph nodes, and grading was also investigated.

Methods: The examination samples were collected from paraffin tissue blocks, from 154 patients. Viral DNA was amplified by the nested-PCR method.

Results: HPV DNA was detected in $29.2 \%$ of the tested samples (in $27.4 \%$ of oropharyngeal and in $30.4 \%$ of oral cavity). The HPV type 16 was detected in $15.6 \%$ of all samples, and in $53.3 \%$ of HPV-positive group. In HPV-positive samples from oropharyngeal HPV 16 constitute $76.5 \%$, and in HPV-positive samples from oral cavity HPV 16 constitute $39.3 \%$. Mixed infection (more than one type of HPV) was observed in 23.5 and $60.7 \%$, respectively, and in $46.7 \%$ of all HPV-positive samples, and in $12.3 \%$ of the whole study group. EBV DNA was detected in $27.3 \%$ of the cases and HPV-EBV co-infection in $7.8 \%$ of samples.

Conclusions: In major patients from Southeastern region of Poland with oropharyngeal cancer HPV type 16 was detected but in oral cavity cancer other mixed infections were observed (i.e. 51, 52, 59, 66, 68, 71, 74). HPV 16 was detected more often among patients younger than 50 years of age, whereas the mixed HPV in the group aged 50-59. The pathogenesis of oral squamous cell carcinoma may be connected with EBV infection. Future studies on the mechanisms of HPV/EBV co-infection and/or superinfection and their role in oral squamous cell carcinoma are necessary.
\end{abstract}

Keywords: Epstein-Barr virus, Human papillomavirus, Oral and oropharyngeal squamous cell carcinoma (OSCC), Co-infection

\section{Introduction}

Oral squamous cell carcinoma (OSCC) is a serious public health problem in many parts of the world and in Poland too. In Poland oral and oropharyngeal cancer constitutes $3.8 \%$ cancers among men and $1.3 \%$ cancers among women [1]. Oral and oropharyngeal squamous cell carcinoma (OSCC) in tumor histology accounts for more than $90 \%$ of the cases [2]. The etiology of OSCC is considered to be multifactorial and the factors influencing it include

\footnotetext{
*Correspondence: m.polz@umlub.pl

'Department of Virology, Medical University of Lublin, ul. Chodźki 1, 20-093 Lublin, Poland

Full list of author information is available at the end of the article
}

environmental factors, life style, infection agents and genetic alterations. The main predisposing factors are tobacco and alcohol abuse [3]. An important role in the etiology of many of them is played by the oncogenic viruses [2]. The cancerogenecity of HPV in humans was conducted by the International Agency for Research on Cancer (IARC) in 2007 and $2012[4,5]$.

The first original observation that implicated HPV as a risk factor in the development of oral cancer was presented by Syrjänen et al. in 1983 [6]. Since then, several studies have focused on HPV detection in oral cancer [7]. A more recent study by Syrjänen and Syrjänen showed a strong association between the presence of HPV DNA, 
specifically HPV16, and OSCC [8]. This meta-analysis showed that HPV significantly increases the risk for OSCC, as compared with controls. HPV positive oropharyngeal cancer varied according to the geographical region, i.e. in North America - $56 \%$, in Japan $52 \%$, in Australia $45 \%$, in Northern and West Europe 38 \% [9].

Epstein-Barr virus, which is also known as human herpesvirus 4 (HHV-4) and which belongs to the Herpesviridae family, has a double-stranded DNA genome [10]. EBV is an enveloped virus with icosahedral capsids symmetry and the genome takes on a linear form in mature virions and a circular episomal form during the period of latency in the infected cells. This is one of the most common viruses in humans [11]. EBV was the first human virus to which the oncogenic potential was attributed, and it is classified as group 1 carcinogen by the World Health Organization's International Agency for Research on Cancer [12]. EBV is correlated with nasopharyngeal and gastric carcinoma, squamous cell carcinoma, Hodgkin's lymphoma, and Burkitt's lymphoma [10, 13-15]. Current investigations suggest that EBV is correlated with many diseases localized in the oral cavity such as gingivitis, periodontitis, pulpitis, periapical inflammations and periodontal abscesses [14, 16]. A lot of studies indicate co-infection with HPV and EBV viruses in oral squamous cell carcinoma $[17,18]$.

The aim of this study was to analyze the prevalence of HPV and EBV and their co-infection in oral and oropharyngeal squamous cell carcinoma in south-eastern Poland.

\section{Material and methods Sample collection}

Tissue samples were obtained from 154 patients with primary oral and oropharyngeal SCC treated in the Chair and Department of Otolaryngology and Laryngological Oncology of the Medical University of Lublin. Samples were collected in 2006-2009. The group consisted of 131 males and 23 females, aged between 40 and 87 (average 56.8 years). In the examination group there were 92 patients with oral, and 62 with oropharyngeal SCC. It was a retrospective investigation and the examined materials were obtained from formalinfixed, paraffin-embedded tissues. The samples were collected during surgery, but TNM was calculated during primary diagnosis (T-tumor, $\mathrm{N}$-nodus, $\mathrm{M}$-metastasis). One hundred percent of the patients were classified as N0, M0. The patients were treated surgically with or without postoperative radiotherapy, depending on the clinical stage of the disease. The patients did not receive radiotherapy or chemotherapy before. TNM classification was done according to the criteria of the Union Against Cancer (UICC) [19]. Histological grading was performed according to the World Health Organization criteria, which divide tumors into three types: well differentiated (G1), moderately differentiated (G2), and poorly differentiated (G3) [20].

This research was approved by the Ethics Committee and it was is in accordance with the GCP regulations (no. KE-0254/181/2012).

\section{DNA extraction from paraffin sections}

We used $5 \times 10-\mu \mathrm{m}$ sections of formalin-fixed, paraffinembedded tissues from OSCC samples. DNA was extracted using a protocol as described in the DNeasy Tissue Kit Handbook (Qiagen GmBH, Hilden, Germany, cat. No 69506). Purified DNA was quantified by spectrophotometry (Epoch Microplate Spectrophotometr, BioTek Instruments Inc., Vinooski, Vermont USA).

\section{EBV DNA detection}

The nested PCR was carried out for detection of EBV DNA. The product size was $54 \mathrm{bp}$. The primer sequences are:

$$
\begin{aligned}
& \text { Outer } \\
& \text { 5' - GTC ATC TAC GGG GAC ACG GA - 3' } \\
& \text { 5' - AAG AAG AGA TAT GTG GGG GT - 3' } \\
& \text { Inner } \\
& \text { 5' - ACC CGG AGC CTG TTT GTG GC- 3' } \\
& 5^{\prime} \text { - GGA GAA GGT CTT CTC GGC CTC - 3' }
\end{aligned}
$$

All PCR reactions were carried out in the final volume of $25 \mu \mathrm{l}$ using Taq PCR Core Kit (Qiagen, Hilden, Germany). Concentrations of PCR reaction components were prepared as follows: $2 \mathrm{mM} \mathrm{MgCl} 2,0.2 \mathrm{mM}$ dNTPs, $0.2 \mu \mathrm{M}$ of each forward and reverse primers and $0.5 \mathrm{U}$ of Taq DNA polymerase. During each run the samples were tested together with one negative and one positive control. The negative control consisted of nuclease-free water, positive - EBV-positive cell line, Namalwa, ATCC-CRL1432. The reaction mixture containing $5 \mu \mathrm{l}$ of extracted DNA was amplified under the following conditions: $94{ }^{\circ} \mathrm{C}$ for $3 \mathrm{~min}$ of initial denaturation, then 35 cycles of $94{ }^{\circ} \mathrm{C}$ for $30 \mathrm{~s}, 55^{\circ} \mathrm{C}$ for $40 \mathrm{~s}, 72{ }^{\circ} \mathrm{C}$ for $1 \mathrm{~min}$ with the final extension at $72{ }^{\circ} \mathrm{C}$ for $5 \mathrm{~min}$. The second round amplification was performed with $1 \mu \mathrm{l}$ of the outer product in the same conditions. The final PCR products were analysed on $3 \%$ agarose gel.

HPV DNA detection; HPV detection and genotyping was performed using the INNO-LiPA HPV Genotyping Extraassay (Innogenetics N. V, Gent, Belgium; no cat. $81063)$ according to the manufacturer's protocol. The kit is based on the amplification of a $65 \mathrm{bp}$ fragment from the L1 region of the HPV genome. PCR products are subsequently typed with the reverse hybridization assay. The assay covers all currently known high-risk HPV genotypes and probable high-risk HPV genotypes $(16,18,26$, $31,33,35,39,45,51,52,53,56,58,59,66,68,73,82)$ as well as a number of low-risk HPV genotypes $(6,11,40,43$, $44,54,70)$ and some additional types $(69,71,74)$. 


\section{Statistical analysis}

Statistical analysis was performed to investigate the relationship between EBV and HPV presence and clinical and demographical characteristics of patients were determined by means of Pearson's chi-square test and with Fisher's exact test for small groups. Statistical significance was defined as $p<0.05$.

\section{Results}

Males (85.1\%) with, smoking (85.0 \%) and alcohol abuse $(64.3 \%)$ problems prevailed in the studied group. The majority of the tumors in the examination group were classified as G2 (81.8 \%). T4 (58.4\%) and N2 (50.0\%) traits occurred in the majority of patients. No cases of metastasis were observed (M0 $100 \%$ ). Characteristics of the study group are shown in Table 1 . In the Fig. 1 the prevalence of HPV, EBV and HPV/EBV co-infection were presented.
Of all 154 samples, $29.2 \%$ (45/154) were HPV positive, $27.4 \%(17 / 62)$ in oropharyngeal and $30.4 \%(28 / 92)$ in oral cavity cancer. HPV type 16 was detected in $20.9 \%(13 / 62)$ of oropharyngeal and in $12 \%$ (11/92) of oral cancer. The HPV type 16 was detected in $53.3 \%$ of HPV-positive group; in oropharyngeal more often $(76.5 \%)$ than in samples from the oral cavity (39.3\%). This difference is statistically significant $(p<0.01)$. Other mixed infections (more than one type of HPV i.e. 51, 52, 59, 66, 68, 71, 74) were detected in 23.5 and $60.7 \%$ of the cases, respectively, and in $46.7 \%$ of all HPV-positive samples.

Of all investigated samples, $27.3 \%$ were positive for EBV, in oropharyngeal $29.1 \%$ and in oral cavity $26.1 \%$. Co-infection HPV/ EBV was detected in $7.8 \%$ (12/154), in oropharyngeal $9.7 \%(6 / 62)$ and in the oral cavity $6.5 \%(6 / 92)$. EBV and HPV 16 co-infection was detected in 6 cases i.e. $50.0 \%$ of co-infected samples. There are no correlation between HPV or EBV infection and age and tobacco smoking (Table 2). Table 3 shows the prevalence

Table 1 Epidemiological and clinical characteristics of patients

\begin{tabular}{|c|c|c|c|c|c|c|c|}
\hline & & \multicolumn{2}{|c|}{ Oropharynx } & \multicolumn{2}{|c|}{ Oral cavity } & \multicolumn{2}{|l|}{ Total } \\
\hline & & $N=62$ & $\%$ & $N=92$ & $\%$ & $N=154$ & $\%$ \\
\hline \multirow[t]{2}{*}{ Sex } & female & 6 & 9.7 & 17 & 18.5 & 23 & 14.9 \\
\hline & male & 56 & 90.3 & 75 & 81.5 & 131 & 85.1 \\
\hline \multirow[t]{3}{*}{ Age } & $40-49$ & 12 & 19.3 & 23 & 25.0 & 35 & 22.8 \\
\hline & $50-59$ & 46 & 74.2 & 60 & 65.2 & 106 & 68.8 \\
\hline & $70+$ & 4 & 6.5 & 9 & 9.8 & 13 & 8.4 \\
\hline \multirow[t]{2}{*}{ Place of residence } & urban & 37 & 59.7 & 55 & 59.8 & 92 & 59.7 \\
\hline & rural & 25 & 40.3 & 37 & 40.2 & 62 & 40.3 \\
\hline \multirow[t]{3}{*}{ Smoking } & yes & 52 & 83.9 & 79 & 85.9 & 131 & 85.1 \\
\hline & no & 3 & 4.8 & 5 & 5.4 & 8 & 5.2 \\
\hline & No answer & 7 & 11.3 & 8 & 8.7 & 15 & 9.7 \\
\hline \multirow[t]{3}{*}{ Alkohol abuse } & yes & 42 & 67,7 & 57 & 62.0 & 99 & 64.3 \\
\hline & No & 7 & 11.3 & 6 & 6.5 & 13 & 8.4 \\
\hline & No answer & 13 & 21.0 & 29 & 31.5 & 42 & 27.3 \\
\hline \multirow[t]{3}{*}{ Histology stage G } & 1 & 2 & 3.2 & 12 & 13.0 & 14 & 9.1 \\
\hline & 2 & 50 & 80.6 & 76 & 82.6 & 126 & 81.8 \\
\hline & 3 & 10 & 16.2 & 4 & 4.4 & 14 & 9.1 \\
\hline \multirow[t]{4}{*}{ T stage } & 1 & 0 & 0 & 0 & 0 & 0 & 0 \\
\hline & 2 & 2 & 3.3 & 31 & 33.7 & 33 & 21.4 \\
\hline & 3 & 12 & 19.4 & 19 & 20.7 & 31 & 20.2 \\
\hline & 4 & 48 & 77.4 & 42 & 45.6 & 90 & 58.4 \\
\hline \multirow[t]{4}{*}{ N stage } & No & 11 & 17.7 & 19 & 20.6 & 30 & 19.5 \\
\hline & N1 & 14 & 22.6 & 18 & 19.6 & 32 & 20.8 \\
\hline & $\mathrm{N} 2$ & 35 & 56.5 & 42 & 45.7 & 77 & 50.0 \\
\hline & N3 & 2 & 3.2 & 13 & 14.1 & 15 & 9.7 \\
\hline \multirow[t]{2}{*}{ M stage } & 0 & 62 & 100.0 & 92 & 100.0 & 154 & 100.0 \\
\hline & 1 & 0 & 0 & 0 & 0 & 0 & 0 \\
\hline
\end{tabular}




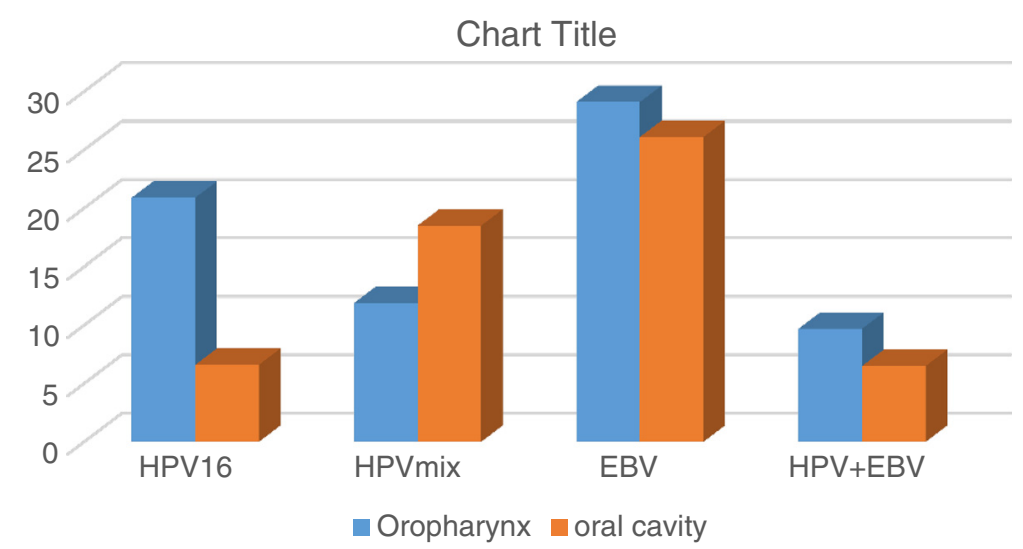

Fig. 1 Prevalence of HPV, EBV and HPV/EBV coinfection in oropharyngeal and oral cavity cancer (\%)

of HPV and EBV in different histopathological grades and TN classification. Among HPV-positive patients G1 was diagnosed more often (15.6 \%) than among HPV-negative ones (6.4\%), and G3 more often in HPV-negative. There is a statistically significant $(p<0.05)$.

\section{Discussion}

The prevalence of HPV in squamous cell carcinoma of the oral and oropharynx is diverse and ranges from 8 to $74 \%$ [21-24]. This is the first original observation about frequency of HPV and EBV in oral and oropharyngeal cancer among Polish patients. In our study HPV DNA was detected in $29.2 \%$ of the tested samples $(27.4 \%$ - oropharynx; $30.4 \%$ - oral cavity) and is lower than in Northern and Western Europe. Poland is located in East Europe, so prevalence of HPV be able to different than in other

Table 2 HPV 16, HPV other and EBV by age and smoking

\begin{tabular}{llll}
\hline Age & HPV 16 & HPV mix & EBV \\
& $N=24$ & $N=21$ & $N=42$ \\
\hline $40-49$ & $8(22.9 \%)$ & $6(17.1 \%)$ & $5(14.3 \%)$ \\
$N=35$ & & & \\
$50-59$ & $13(12.3 \%)$ & $15(14.2 \%)$ & $33(31.4 \%)$ \\
$N=106$ & & & \\
$70+$ & $3(23.1 \%)$ & 0 & $4(30.8 \%)$ \\
$N=13$ & & & $>0.05$ \\
$P$ & $>0.05$ & $15(71.4 \%)$ & $32(76.2 \%)$ \\
Smoking & $20(83.3 \%)$ & & \\
Yes & & & $10(23.8 \%)$ \\
$N=131$ & & $6(28.6 \%)$ & $>0.05$ \\
No & $4(16.7 \%)$ & $>0.05$ & \\
$N=23$ & & & \\
$P$ & & &
\end{tabular}

European countries. HPV infection is a sexually transmitted infection, so sexual behaviors can play a role.

Studies by Robinson et al. [25] did not reveal any association between the histological grade and HPV status in these tumours. Instead, Zhao et al [26] by multivariate analysis have found a correlation between HPV infection and poor histological grade (OR = 104.0, $95 \%$ CI: $11.2-$ 962.1). His study provides evidence that the presence of HPV predicted a better survival.

In the present study a significant relationship was found between the status of HPV and the poor histopathological grades (chi square, $p<0.05$; Table 3 ). In most studies no association was found between HPV presence and TNM clinical stage [26]. Our results are similar.

Confirmation or exclusion of HPV DNA in OSCC influences prognosis and therapy choices. Some researchers state that OSCC patients who are HPV-positive have a more favorable treatment prognosis [20-22], higher survival rates and a lower risk of the disease recurrence in comparison to the HPV-negative patients [27]. Additionally, such patients do not require radio or chemotherapy afterwards [28], and according Khode [29] HPV-positive tumors are more sensitive to chemotherapy.

Although squamous cell carcinoma has been commonly believed to affect people above fifty, the newest data indicate that the age of people afflicted with this disease is constantly decreasing [30]. The study by Golusiński et al. [30] on the occurrence of this disease in people under 45 years of age indicates that these cases constitute up to $0.24-9.0 \%$ of all cases, and that this problem is relatively new. These data show that oral and oropharynx cancers are common among people over 50; however, they also occur at a younger age (80.8 and $19.2 \%$, respectively) [31]. Among patients younger than $50 \mathrm{HPV} 16$ was detected more often $(22.9 \%)$ than in the group aged 50-59 (12.3\%). In patients 70 years and over was only $3 \mathrm{HPV}$ positive cases (Table 2). 
Table 3 Prevalence of HPV and EBV in different histopathological grades and TN classification

\begin{tabular}{|c|c|c|c|c|c|}
\hline & $\mathrm{HPV}+n=45$ & $\mathrm{HPV}-n=109$ & $\mathrm{EBV}+n=42$ & $E B V-n=112$ & $p$ value \\
\hline G1 & $7(15.6)$ & $7(6.4)$ & $4(9.5)$ & $10(8.9)$ & $>0.05$ \\
\hline \multicolumn{6}{|c|}{$n=14$} \\
\hline G2 & $37(82.2)$ & $89(81.7)$ & $34(81.0)$ & $92(82.2)$ & \\
\hline \multicolumn{6}{|c|}{$n=126$} \\
\hline G3 & $1(2.2)$ & $13(11.9)$ & $4(9.5)$ & $10(8.9)$ & \\
\hline \multicolumn{6}{|c|}{$n=14$} \\
\hline$P$ & $<0.05^{*}$ & & $>0.05$ & & \\
\hline $\mathrm{T} 1$ & 0 & 0 & 0 & 0 & $>0.05$ \\
\hline \multicolumn{6}{|c|}{$n=0$} \\
\hline $\mathrm{T} 2$ & $7(15.6)$ & $26(23.8)$ & $6(14.3)$ & $27(24.1)$ & \\
\hline \multicolumn{6}{|c|}{$n=33$} \\
\hline T3 & $9(20.0)$ & $22(20.2)$ & $8(19.0)$ & $24(21.4)$ & \\
\hline \multicolumn{6}{|c|}{$n=31$} \\
\hline T4 & $29(64.4)$ & $60(55.0)$ & $28(66.7)$ & $61(54.5)$ & \\
\hline \multicolumn{6}{|c|}{$n=89$} \\
\hline$p$ & $>0.05$ & & $>0.05$ & & \\
\hline No & $6(13.3)$ & $24(22.0)$ & $26(61.9)$ & $4(3.6)$ & $>0.05$ \\
\hline \multicolumn{6}{|c|}{$n=30$} \\
\hline N1 & $6(13.3)$ & $26(23.9)$ & $7(16.7)$ & $25(22.3)$ & \\
\hline \multicolumn{6}{|c|}{$n=32$} \\
\hline N2 & $25(55.6)$ & $52(47.7)$ & $7(16.7)$ & $70(62.5)$ & \\
\hline \multicolumn{6}{|c|}{$n=77$} \\
\hline N3 & $8(17.8)$ & $7(6.4)$ & $2(4.7)$ & $13(11.6)$ & \\
\hline \multicolumn{6}{|c|}{$n=15$} \\
\hline$p$ & $>0.05$ & & $>0.05$ & & \\
\hline
\end{tabular}

Smokers prevailed among patients infected both with $\mathrm{HPV}$ and EBV. It was found out that the largest number of smoking patients were in the group infected with HPV 16 virus ( $83.3 \%$; Table 2). Probably, there is a correlation between smoking and HPV 16 infection on the one hand and oropharyngeal squamous cell carcinoma, on the other [32]. Merne et al. [33] suggest a possible synergy between tobacco components and viral oncogenes, especially HPV16 E6/E7 in transformation of oral epithelial cells. Studies by Haukioja et al. [34] found out that smoking is a risk factor for a persistent oral HPV infection. On the other hand, persistent HPV infection in the oral mucosa might increase the risk of developing oral cancer [35].

A number of authors emphasize the role of EBV in the development of OSCC [14, 15, 20].

Zur Hausen drew attention as early as 1976 to the possibility of the involvement of EBV in human cancer [36]. Jaloluli et al. [18] observed the presence of EBV in $55 \%$ of samples from 8 different countries. The frequency of occurrence of EBV virus varies in different populations.
Opinions on the role of EBV in OSCC are different. Literature provides a wide range of preponderance for oral, pharynx and larynx viral infections. Nevertheless, the obtained research results suggest that the pathogenesis of oral squamous cell carcinoma is not directly connected with Herpesviridae infection in the oral cavity [37]. EBV DNA was detected in our research in $27.3 \%$ of the cases (42/154), most often in the 50-59 years old group (31.4\%; Table 2). The frequency of EBV DNA in oropharyngeal cancer was slightly higher $29 \%$ (18/62) compared with the oral cavity - $26.1 \%$ (24/92) (Fig. 1). This low infection rate may result from the fact that formalin-fixed, paraffinembedded tissues was examined.. The presence of the EBV is most likely connected with more aggressive types of oral tumors, particularly in groups of immunosuppressed patients [38]. Infection with EBV can be of importance since EBV is widespread in the human population (antibodies to EBV have approximately $95 \%$ of adults). The infection may be asymptomatic and life-long [39]. According to Kis et al. [40], the prevalence of Epstein-Barr virus in OSCC patients is significantly higher than in the healthy group 
and higher than that in other mucosa pathologies such as oral leukoplakia and oral lichen planus $(73.8,19.1,29.5$ and $46.6 \%$, respectively).

Some authors find a connection between EBV infection (especially co-infection with papillomaviruses) and squamous cell carcinoma of the tongue and oropharyngeal sites [14, 17, 41]. In our study HPV-EBV co-infection was detected only in $7.8 \%$ of samples (Fig. 1). This low percentage can not support that co-infection plays a role in OSCC. However, it cannot be completely exluded. Jalouli et al. [42] studied tissue samples obtained from patients with oral cancers and they showed that prevalence of HPV and EBV infections is common and may influence the oral cancer development. Co-infection by multiple oncogenic viruses may be an important risk factor in the development of OSCC $[17,43]$. Jiang et al. [17] suggest that coinfected cells can have a higher tumorigenic potential than normal cells, and that co-infection of both HPV and EBV may have a more profound effect on invasion than proliferation.

The question remains whether in these cases we have to do with co-infection or superinfection. It is known that chronic virus infection affects the immunological answer of the host. Primary infection with non-oncogenic virus can favour superinfection with oncogenic virus capable of cancer transformation. The oncogenic potential of HPV is related to the expression of E6 and E7, the oncogenic potential of EBV - to the expression of LMP-1 and LMP-2. Toll-like receptors (TLRs) play a critical role in the early innate immune response to the invading pathogens by sensing a microorganism and they are involved in sensing endogenous danger signals $[44,45]$. Fathallah et al [45] established that the EBV oncoprotein latent membrane protein 1 (LMP1) is a strong inhibitor of TLR9 transcription, which can favour the aforementioned superinfection. A limitation in our studies is a too small number of cases of EBV/HPV, coinfection, which makes the epidemiological analysis of this group of patients impossible.

In conclusion, the present study shows that in major patients from Southeastern region of Poland with oropharyngeal cancer HPV type 16 was detected but in oral cavity cancer other mixed infections were observed (i.e. 51, 52, 59, 66, 68, 71, 74). HPV 16 was detected more often among patients younger than 50 age of years, whereas the mixed HPV in the group aged 50-59. EBV may play a role in the development of OSCC. Future both epidemiological and studies on the mechanisms of co-infection and/or superinfection and their role in oral squamous cell carcinoma are necessary. The knowledge about these mechanisms may provide targets for therapy and for development of diagnostic methods.

\section{Competing interests}

The authors declare that they have no competing interests.
Authors' contribution

DP-G: Conceived of the study, its design, data analysis, manuscript preparation; KM: Data and clinical samples collection; AS: Carried out the molecular identification; MP-D: Data analysis, coordination and helped to draft the manuscript, review; All authors read and approved the final manuscript.

\section{Acknowledgements}

This study was supported by a Research Grant from the Medical University, Lublin, Poland (DS 233).

We are thankful to prof. Wiesław Gołąbek (Chair and Department of Otolaryngology and Laryngological Oncology in Lublin 1998-2010) for his help in clinical material collection.

\section{Author details}

'Department of Virology, Medical University of Lublin, ul. Chodźki 1, 20-093 Lublin, Poland. ${ }^{2}$ Chair and Department of Otolaryngology and Laryngological Oncology, ul. Jaczewskiego 8, 20-054 Lublin, Poland.

Received: 4 May 2015 Accepted: 2 September 2015

Published online: 12 October 2015

\section{References}

1. Didkowska J, Wojciechowska U, Zatoński Z. Cancer in Poland in 2011. Warsaw: Oncology Centre- Oncology Institute Maria Skłodowska- Curie; 2013.

2. Alibek K, Kakpenova A, Yeldar Baiken Y. Role of infectious agents in the carcinogenesis of brain and head and neck cancers. Infect Agent Cancer. 2013;8:7-16.

3. Garbuglia AR. Human papillomavirus in head and neck cancer. Cancers. 2014:6:1705-26.

4. IARC. Monographs on the evaluation of carcinogenic risks to humans. In: Cancer IARC, ed. Lyon, France: World Health Organization; 2007. p. 670.

5. IARC. Monographs on the evaluation of carcinogenic risks to humans A review of human carcinogens. Biological agents. Lyon: World Health Organization; 2012. p. 255.

6. Syrjänen KJ, Syrjänen SM, Lamberg MA, Pyrhönen S. Human papillomavirus (HPV) involvement in squamous cell lesions of the oral cavity. Proc Finn Dent Soc. 1983;79:1-8.

7. Jalouli J, Ibrahim SO, Mehrotra R, Jalouli MM, Sapkota D, Larson PA, et al. Prevalence of viral (HPV, EBV, HSV) infections in oral submucous fibrosis and oral cancer from India. Acta Otolaryngol. 2010;130:1306-311.

8. Syrjänen K, Syrjänen S. Detection of human papillomavirus in sinonasal carcinoma: systematic review and meta-analysis. Hum Pathol. 2013;44:983-91.

9. Gillison M, Castellsague X, Chaturvedi A, Goodman M, Smijders P, Tommasino MA, et al. Comparative epidemiology of HPV infection and associated cancers of the head and neck and cervix. Int J Cancer. 2014;134:497-507.

10. Peh SC, Kim LH, Mun KS, Tam EL, Sam CK, Poppema S. Epstein-Barr virus (EBV) subtypes and variants in malignant tissue from Malaysian patients. J Clin Exp Hematopathol. 2003;43:61-9.

11. Alipov G, Nakayama T, Nakashima M, Wen ChY, Niino D, Kondo H, et al. Epstein-Barr virus-associated gastric carcinoma in Kazakhstan. World J Gastroenterol. 2005;11:27-30.

12. Proceedings of the IARC working group on the evaluation of carcinogenic risks to tumors. Epstein-Barr virus and Kaposi's sarcoma Herpesvirus/Human herpesvirus 8. Lyon, France, 17-24 June 1997. IARC Monogr Eval Cacinog Risks Hum. 1997:70:1-492.

13. Perera RA, Samaranayake LP, Tsang CSP. Shedding dynamics of Epstein-Barr virus: A type 1 carcinogen. Arch Oral Biol. 2010;55:639-47.

14. Slots J, Saygun I, Sabeti M, Kubar A. Epstein-Barr virus in oral diseases. J Periodontal Res. 2006;41:235-44

15. Chen MR. Epstein-Barr virus, the immune system, and associated diseases. Front Microbiol. 2011;2:5.

16. Grinde B, Olsen I. The role of viruses in oral disease. J Oral Microbiol. 2010;12:2.

17. Jiang R, Ekshyyan O, Moore-Medlin T, Rong X, Nathan S, Gu X, et al. Association between human papilloma virus/Epstein-Barr virus co-infection and oral carcinogenesis. J Oral Pathol Med. 2015;44:28-36.

18. Jalouli J, Jalouli MM, Sapkota D, Ibrahim SO, Larron PA, Sand L. Human papillomavirus, herpes simplex virus and Epstein-Barr virus in oral squamous cell carcinomas from eight different countries. Anticancer Res. 2012;32:571-80. 
19. Sobin LH, Gospodarowicz M, Wittekind C, editors. TNM classification of malignant tumours $7^{\text {th }}$ edition. Washington DC: Wiley-Blackwell; 2009. 22-45.

20. Cardesa A, Gale N, Nadal A, Zidor N. Squamous cell carcinoma in World Heath Organization Classifiation of Tumours. Pathology and Genetics: Head and Neck Tumours. Barnes L, Eveson JW, Reichart P, Sidnousky (eds.) Lyon, International Agency for Research on Cancer, 2010; 118-121.

21. Castro Peixoto Patury Galvao T, Busolotti I. Prevalance of Human papillomavirus (HPV) in oral and oropharynx. Rev Bras Otorrinolaringol. 2006:2:1-14

22. Ritchie JM, Smith EM, Summersgill KF, Hoffman HT, Wang D, Klussmann JP, et al. Human papillomavirus infection as a prognostic factor in carcinomas of the oral cavity and oropharynx. Int J Cancer. 2003;104:336-44.

23. Wang D, Ritchie JM, Smith EM, Zhang Z, Turek LP, Haugen TH. Alcohol dehydrogenase 3 and risk of squamous cell carcinoma of the head and neck. Cancer Epidemiol Biomarkers Prev. 2005;14:626-33.

24. Sathish N, Wang X, Yuan Y. Human Papillomavirus (HPV)-associated oral cancers and treatment strategies. J Dent Res. 2014;93:29S-36S.

25. Robinson M, Suh Y, Paleri V, Devlin D, Ayaz B, Pertl L, et al. Oncogenic human papillomavirus-associated nasopharyngeal carcinoma: an observational study of correlation with ethnicity, histological subtype and outcome in a UK population. Infect Agent Cancer. 2013:8:30.

26. Zhao D, Xu Q, Chen X, Fan M. Human Papillomavirus as an Independent Predictor in Oral Squamous Cell Cancer. Int J Oral Sci. 2009:1:119-25.

27. Mirghani H, Amen F, Moreau F, Guigay J, Ferchion M, Melkane AE, et al. Human papillomavirus testing in oropharyngeal squamous cell carcinoma: What the clinician should know. Oral Oncol. 2014;50:1-9.

28. Benson E, Li R, Eisele D, Fakhry C. The clinical impact of HPV tumor status upon head and neck squamous cell carcinoma. Oral Oncol. 2014;50:565-74

29. Khode SR, Dwivedi RC, Rhys-Evans P, Kazi R. Exploring the link between human papilloma virus and oral and oropharyngeal cancers. J Cancer Res Ther. 2014;10:492-98.

30. Golusiński W, Waśniewska E, Kaczmarek J, Kędzia D, Wróbel M, Malinowska B. Patients under 45 years of age "young adults" with head and neck squamous cell carcinoma. Retrospective, multivariable analysis-preliminary report. Otolaryngol Pol. 2003;57:185-9.

31. Wojciechowska U, Didkowska J, Zatoński W. Cancer in Poland in 2003. Warsaw, Poland: Oncology Centre- Oncology Institute Maria Skłodowska- Curie; 2005.

32. Chakrobarty B, Roy JG, Majumdar S, Uppala D. Relationship among tobacco habits, human papilloma virus (HPV) infection, p53 polymorphism/mutation and the risk of oral squamous cell carcinoma. J Oral Maxillofac Pathol. 2014;18:211-6.

33. Merne M, Rautava J, Ruutu M, Syrjanen S. Smokeless tobacco increases aneuploidy in oral HPV16E6/E7-transformed keratinocytes in vitro. J Oral Pathol Med. 2014;43:685-90.

34. Haukioja A, Asunta M, Söderling E, Syrjänen S. Persistent oral human papillomavirus infection is associated with smoking and elevated salivary immunoglobulin G concentration. J Clin Virol. 2014;61:101-6.

35. Rautava J, Syrjänen S. Human papillomavirus infections in the oral mucosa. J Am Dent Assoc. 2011;142:905-14.

36. Hausen Z. Biochemical approaches to detection of Epstein-Barr virus in human cancer. Cancer Res. 1976;26:678-80.

37. Saravani S, Miri-Moghaddam E, Sanadgol N, Kadeh H, Nazeri MR. Human herpesvirus-6 and Epstein-Barr virus infections at different histopathological grades of oral squamous cell carcinomas. Int J Prev Med. 2014;5:1231-8.

38. Slots J. Herpesviruses in periodontal diseases. Periodontol 2000. 2005:38:33-62.

39. Shah KM, Young LS. Epstein-Barr virus and carcinogenesis: beyond Burkitt's lymphoma. Clin Microbiol Infect. 2009;15:982-88.

40. Kis A, Feher E, Gall T, Tar I, Boda R, Toth ED, et al. Epstein-Barr virus prevalence in oral squamous cell cancer and potentially malignant ora disorders in an eastern Hungarian population. Eur J Oral Sci. 2009;117:537-40.

41. Goldenberg D, Benoit NE, Begun S, et al. Epstein-Barr virus in head and neck cancer assessed by quantitative polymerase chain reaction. Laryngoscope. 2004;114:1027-31.

42. Jalouli J, Ibrahim SO, Sapkota D, Jalouli MM, Vasstrand EN, Horsch JM, et al. Presence of human papilloma virus, herpes simplex virus and Epstein-Barr virus DNA in oral biopsies from Sudanese patients with regard to toombak use. J Oral Pathol Med. 2011;19:599-604

43. Al Moustafa AE, Chen D, Ghabreau L, Akil N. Association between human papillomavirus and Epstein-Barr virus infections in human ora carcinogenesis. Med Hypotheses. 2009:73:184-6.
44. Hasan UA, Bates E, Takeshita F, Biliato A, Accardi R, Bouvard V, et al. TLR9 expression and function is abolished by the cervical cancer-associated human papillomavirus type 16 J Immunol. 2007:178:3186-97.

45. Fathallah I, Parroche P, Gruffat $H$, Zannetti C, Johansson $H$, Yue J, et al. EBV latent membrane protein 1 is a negative regulator of TLR9. J Immunol. 2010;185:6439-47.

\section{Submit your next manuscript to BioMed Central and take full advantage of:}

- Convenient online submission

- Thorough peer review

- No space constraints or color figure charges

- Immediate publication on acceptance

- Inclusion in PubMed, CAS, Scopus and Google Scholar

- Research which is freely available for redistribution 